\title{
A Study of Alcohol Blended Fuels in an Unthrottled Single Cylinder Spark Ignition Engine
}

\author{
Alasdair Cairns, Alan Todd, Neil Fraser \\ MAHLE Powertrain Ltd \\ Pavlos Aleiferis, John Malcolm \\ University College London
}

Copyright $(2010$ SAE International

\begin{abstract}
This work involved study of the effects of alcohol blends on combustion, fuel economy and emissions in a single cylinder research engine equipped with a mechanical fully variable valvetrain on the inlet and variable valve timing on the exhaust. A number of splash blends of gasoline, iso-octane, ethanol and butanol were examined during port fuel injected early inlet valve closing operation, both with and without variable valve timing. Under low valve overlap conditions, it was apparent that the inlet valve durations/lifts required for full unthrottled operation were remarkably similar for the wide range of blends studied. However, with high valve overlap differences in burning velocities and internal EGR tolerances warranted changes in these valve settings. In turn, it was concluded that high ethanol content blends facilitated minimum throttling at the inlet valve itself and the largest relative savings in terms of fuel consumption, engine-out emissions of NOx and (corrected) unburned hydrocarbons.
\end{abstract}

\section{INTRODUCTION}

The ability to vary the inlet and exhaust valve events of the Spark Ignition (SI) engine is well-known to facilitate improved compromise between performance, fuel economy and emissions. Variable Valve Timing (VVT) is one such established technique for improving the fuel economy of the gasoline engine (1-3). There are several mechanisms by which VVT influences fuel consumption:

- Increasing or delaying valve overlap, which increases trapped residuals and reduces pumping work

- Late Inlet Valve Closure (IVC), which decreases pumping losses

- Late Exhaust Valve Opening (EVO), which can increase expansion work

As a result, fuel economy can typically be improved by up to 5\% over the European drive cycle. The choice of optimum VVT strategy is highly dependent on exhaust manifold design, compression ratio, cam phasing limits due to clash, part-load residual dilution tolerance and the importance of Wide Open Throttle (WOT) performance relative to part-load fuel consumption and emissions. A dual-independent VVT strategy offers high overlap potential and reasonable compromise between maximising WOT torque and minimising part-load fuel consumption and emissions. This is particularly true for hardware combinations that benefit from high

Page 1 of 24 
overlap at both WOT (for scavenging) and part-load (to increase trapped residuals). An alternative strategy that could be used is high overlap retard, which can potentially give even lower fuel consumption than a maximum overlap strategy (4). However, WOT torque can be compromised, particularly at low speed unless very wide range, fast response cam phaser units can be used (5).

In relatively recent years, there has also been considerable interest in fully variable valvetrain systems for additional improvements, such as:

- Further reduction in throttling losses via load control directly at the inlet valve(s)

- Increased thermal efficiency through greater expansion ratio

- Reduced tailpipe emissions under cold-start (direct fuel injection) conditions via late Inlet Valve Opening (IVO)

Numerous fully variable valvetrain strategies exist depending on application, but the currently reported work is most concerned with those SI engine strategies claiming to enable improved part-load fuel efficiency. During his useful study in a similar vein, Tuttle compared the effects of Late Inlet Valve Closing (LIVC) and Early Inlet Valve Closing (EIVC) in a single cylinder research engine. In early experiments (6), IVC was delayed by between $60-96^{\circ}$ crank. Fuel consumption was observed to reduce by up to $6.5 \%$ and was accompanied by lower engine-out emissions of NOx ( 24\%) but similar hydrocarbon levels. Regardless, Tuttle concluded that $96^{\circ}$ was the maximum delay that could be tolerated due to loss of effective compression ratio, which would significantly limit the attainable speed-load map (assuming no external compression was available). In subsequent work (7), it was concluded that the EIVC strategy was favourable for part-load, allowing de-throttled operation over a wider speed-load window, albeit reliant on $200^{\circ}$ crank range of inlet valve closing.

To date, there still remains significant research interest in the thermodynamic effects of EIVC operation. For example, in a recent alternative study Cleary and Silvas (8) investigated EIVC at part-load (1300rpm/3.3bar net IMEP) in a single cylinder PFI engine. It was observed that such a strategy led to reduced in-cylinder turbulence at the conditions studied, associated with the increased time under closed valve conditions. In turn, this resulted in prolonged combustion duration, reduced in-cylinder gas temperatures, reduced engine-out emissions of NOx (up to 25\%) and increased values of unburned hydrocarbons (also 25\%). The deterioration in burn rate could be reduced by switching to a LIVO strategy but, under the reduced valve duration conditions tested, the pumping losses were worse than the conventional throttled benchmark case.

The benefits achieved by EIVC operation are highly dependent on the valvetrain system employed. At one end of the spectrum, various electro-magnetic and electro-hydraulic systems have been proposed. Such camless systems have been reported to allow the greatest potential for reduction in SI engine breathing losses $(9,10)$ and/or can be used to realize advanced modes of operation such as Controlled Auto Ignition (11, 12). However, in general these systems often still have significant issues to overcome including packaging, noise and cost. Therefore, the majority of fully variable valvetrain systems entering production have been mechanically based as these arguably present a viable step on a cost-benefit basis. For example, Unger et al. (13) recently summarised the design and development of the second generation Valvetronic system, capable of providing up to $\sim 12 \%$ reduction in fuel consumption at part-load (albeit unspecified where). Improvements claimed in the second-generation iteration included more aggressive valve lift profiles, re-optimization of the inlet port masking, friction reductions and integration of the control system within the main engine control unit. Elsewhere, Shimizu and co-workers (14) recently reported on the benefits of the new production Valvematic system, a well-packaged continuously variable valve lift system offered in conjunction with dual VVT. These workers reported up to $\sim 10 \%$ improvement in fuel economy could be achieved during steady state part-load operation, with similar percent improvement in power. Another mechanical fully variable system recently

Page 2 of 24 
introduced is the Nissan VVEL $(15,16)$, which enables relatively aggressive inlet lift profiles to be used with fuel economy benefits similar to those above. Elsewhere, Sellnau and co-workers (17) have demonstrated how two-stage mechanical valve actuation can allow viable further compromise on a cost-benefit basis, achieving $5.5 \%$ improvement in fuel economy and $\sim 46 \%$ reduction in NOx over an Environmental Protection Agency (EPA) drive cycle.

The above systems were all used with port fuel injection. However, the combination of EIVC with homogeneous Direct Injection (DI) has also begun to warrant interest, with the potential for further fuel savings if used together with increased compression ratio. For example, workers on the "Hotfire" collaborative project recently examined such effects in both optical and thermodynamic single cylinder SI engine assemblies (18, 19). During this study, greatest fuel consumption benefits could be achieved if just one of the two inlet valves was actuated. However, the swirl dissipated quickly once the valve closed and the fuel economy benefits recorded varied substantially depending on which of the two inlet valves was activated.

In recent years there has also been significant worldwide interest in alcohol-based fuels for future SI engines. Such fuels may present one viable renewable solution, with the potential to be used in a near $\mathrm{CO}_{2}$-neutral manner through efficient conversion of biomass (20). First generation biofuels for SI applications have so far largely been based on gasoline-ethanol blends (21-23), where current fuel quality standards typically allow between 5-10\% inclusion of ethanol within an existing gasoline pool. The main exception to this is Brazil, where alcohol fuels largely produced from sugar cane are widely available in anhydrous "gasohol” up to neat ethanol form (24). Elsewhere, gasoline containing up to 85\% ethanol (“E85”) has emerged as a passenger car fuel, but so far mainly as a niche product, with flex-fuel operation still required (25). The main objective of the currently reported work was to improve general understanding of the combustion, fuel economy and emissions behaviour of potential next generation biofuels during part-load EIVC operation. This topic so far appears to have been the subject of little research presented within the public domain. The nearest relevant publications readily available involve reduced part-load throttling with alcohol fuels via exhaust gas recirculation $(26,27)$.

\section{EXPERIMENTAL SETUP}

\section{ENGINE ASSEMBLY}

The experiments were performed in a naturally aspirated single cylinder four-valve per cylinder spark ignition research engine. Some general details of the unit are presented below in Table 1.

\begin{tabular}{|l|l|}
\hline No of cylinders & 1 \\
\hline Bore $(\mathrm{mm})$ & 82.5 \\
\hline Stroke $(\mathrm{mm})$ & 88.9 \\
\hline Geometric compression ratio & $9.8: 1$ \\
\hline Variable Valve Timing & Fully Variable (Inlet \& Exhaust) \\
\hline Fuel injection & Port \\
\hline Spark plug & NGK single electrode \\
\hline
\end{tabular}

Table 1: Basic engine characteristics

The base engine assembly is illustrated in Figure 1. The engine was designed to provide a low-cost single cylinder assembly. As such, the bottom-end was based on a modified industrial Lister-Petter diesel engine sub-

Page 3 of 24 
assembly, re-fitted with a prototype water-cooled barrel and bespoke con-rod and piston assemblies. A section through the prototype cylinder head assembly is illustrated in Figure 2, with the location of the port fuel injector and central spark plug used throughout the currently reported work indicated. The ports and combustion chamber geometry were based on those of a known production engine (Audi 2.0 litre FSI, but with the exception of smaller exhaust valves to allow the option of central DI to be studied in other work). The port fuel injector used in the currently reported study was also a production part, with four fuel sprays designed to straddle the valve stem and allow fuel injector targeting toward the back of a warm, closed valve. A picture of the flat-topped piston used throughout the study is set out in Figure 3. This modular single cylinder assembly allowed straightforward conversion between the existing thermodynamic setup and fully optical operation, with the latter demonstrated recently under both port and side direct fuel injection operation (28, 29). During the currently reported work, the engine remained set up in thermodynamic mode.

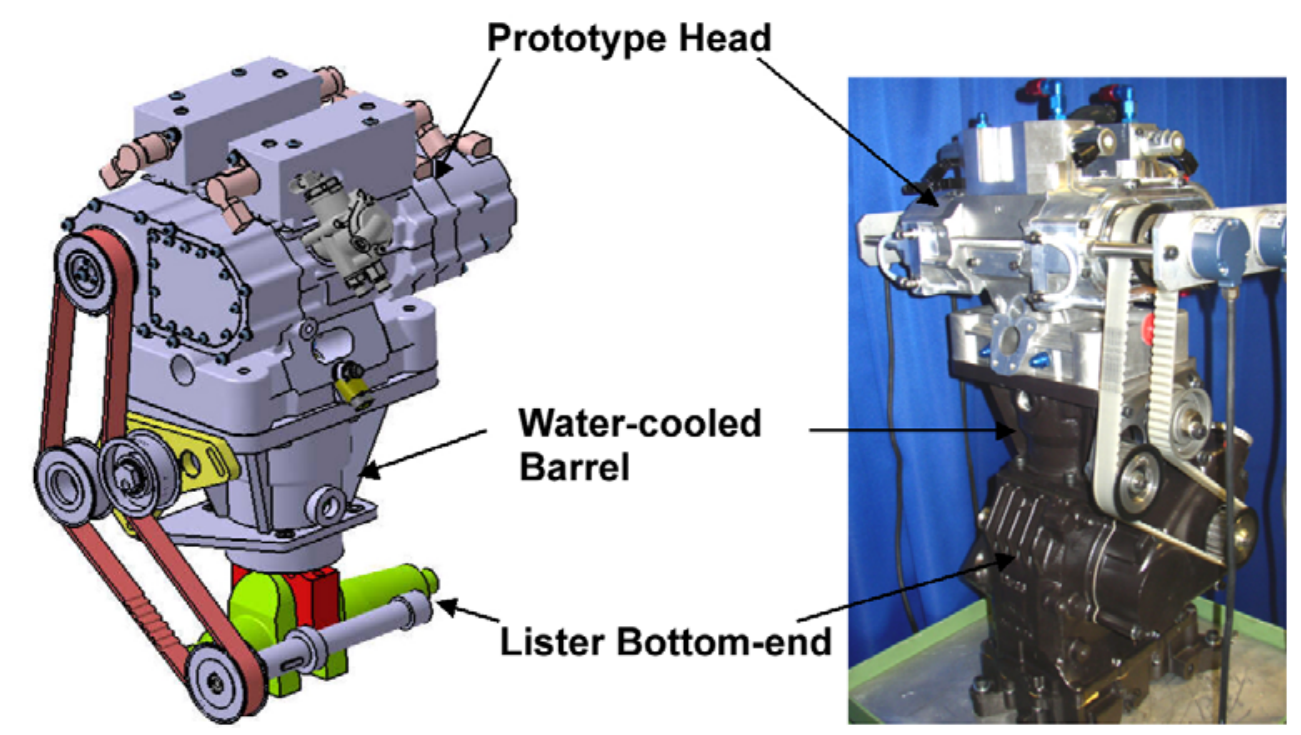

Figure 1: Base engine assembly (thermodynamic setup)
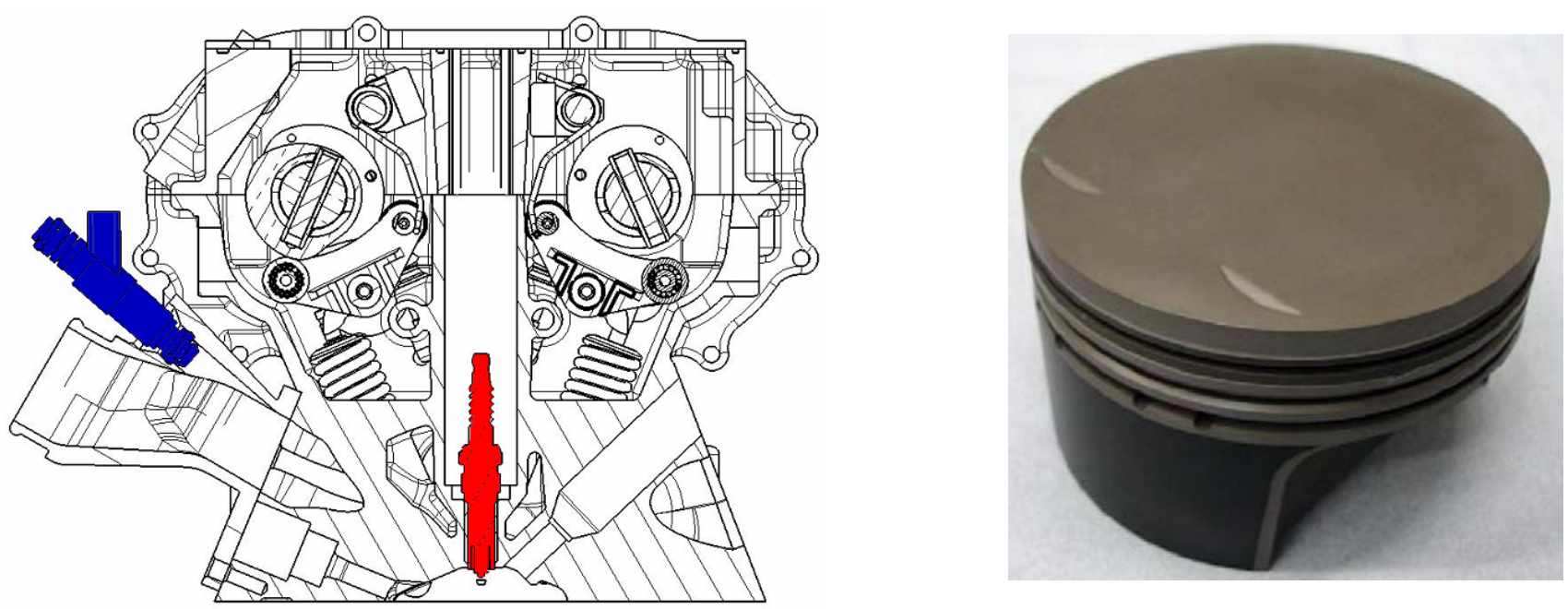

Figure 2: a) Cylinder head assembly showing the port fuel injection setup and b) the corresponding flat-topped piston 
The prototype cylinder head included a mechanical fully variable valvetrain assembly, fitted to both the inlet and exhaust. The system used was an evolution of the MAHLE Variable Lift and Duration (VLD) mechanism, previously introduced in detail elsewhere $(30,31)$. In brief, the system is based on a shaft-in-shaft cam operating principle. An example of an inlet VLD mechanism is illustrated in Figure 3. The two opening cams are pressed on to the outer shaft. These cams are equivalent in profile and must open the two inlet valves in a synchronous fashion via the lever assembly. The opening cam contours were designed so that, if no closing cam were available, the inlet valves would remain open at maximum lift for a prolonged period before eventually closing in a safe manner. However, such operation is hypothetical as the closing cam is available and pinned to the inner shaft. The phase of this closing cam, relative to the opening cam, can be advanced so as to close the valve earlier and reduce the valve lift and duration in proportion. The profiles of the cams were designed so as to ensure acceptable dynamic forces were produced regardless of phase.

In summary, the opening and closing cams act in tandem to produce a mean cam (and hence valve) lift curve. By advancing the phasing of the inner shaft relative to the outer shaft, the closing of the valve is advanced, hence allowing reduced lift and duration to be achieved. The phasing of the closing cam was controlled using a prototype wide range $\left(140^{\circ} \mathrm{crank}\right)$ hydraulic cam phaser, denoted in Figure 4 as the "VLD Phaser". In order to then achieve fully variable valvetrain operation, a second hydraulic VVT cam phaser was fixed to the outer tube, providing $40^{\circ}$ crank timing range. Similar ranges were available on the exhaust.

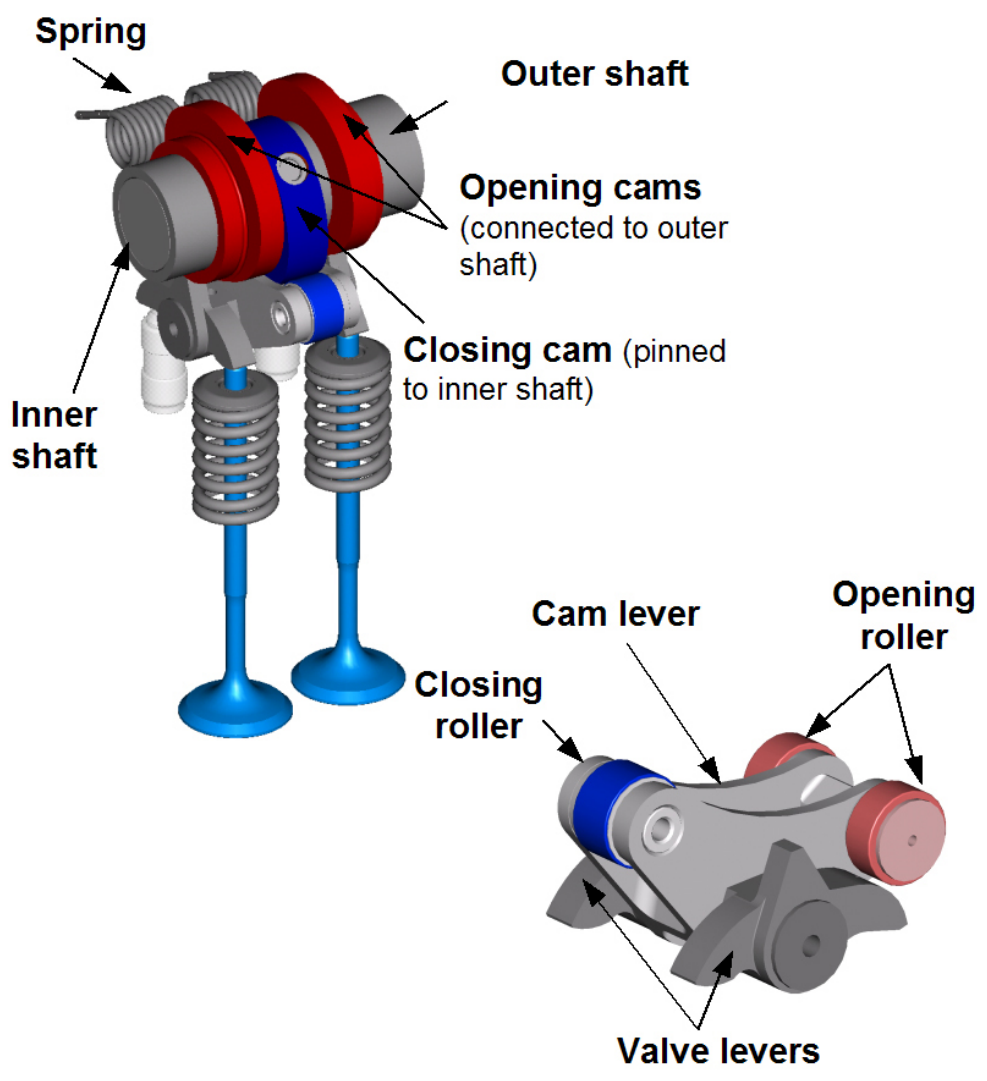

Figure 3: Key VLD components (example shown for inlet VLD operation) 


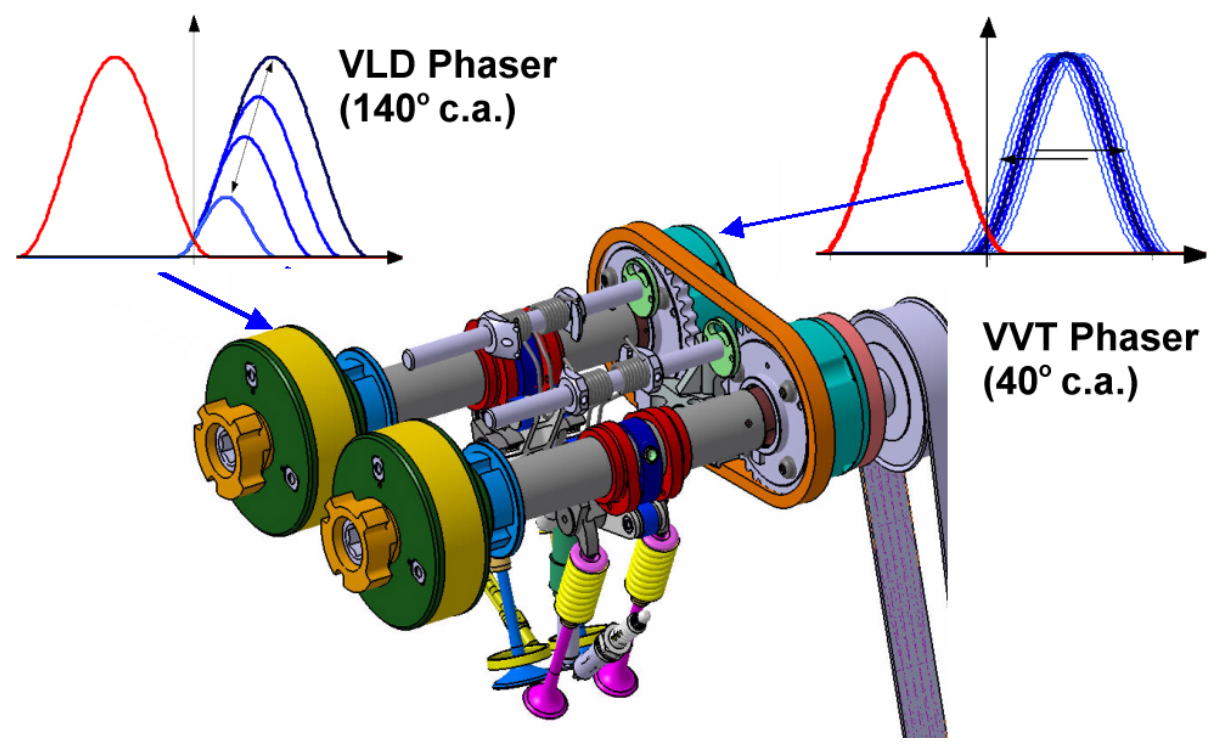

Figure 4: Single cylinder VLD assembly with the VLD and VVT cam phasers of the inlet camshaft identified

\section{VALVE LIFT MEASUREMENTS}

One main objective of the current work was to study the combined effects of unthrottled operation and internal EGR on combustion, performance and emissions with different fuels. An illustration of the valve strategies so far examined is shown in Figure 5. The experiments involved study of EIVC at varied degrees of valve overlap. The exhaust VLD cam phaser remained inactive and was set for maximum valve lift throughout the experiments.

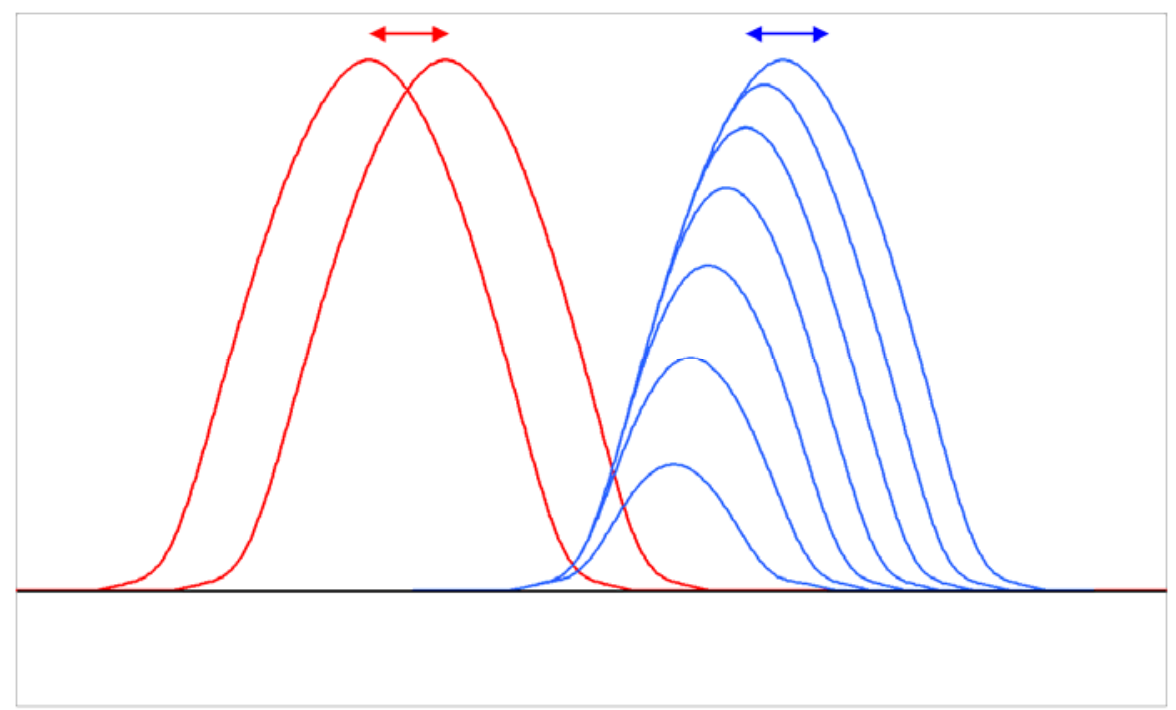

Figure 5: Valve timing strategies studied (continuously variable inlet valve lift, dual independent VVT) 

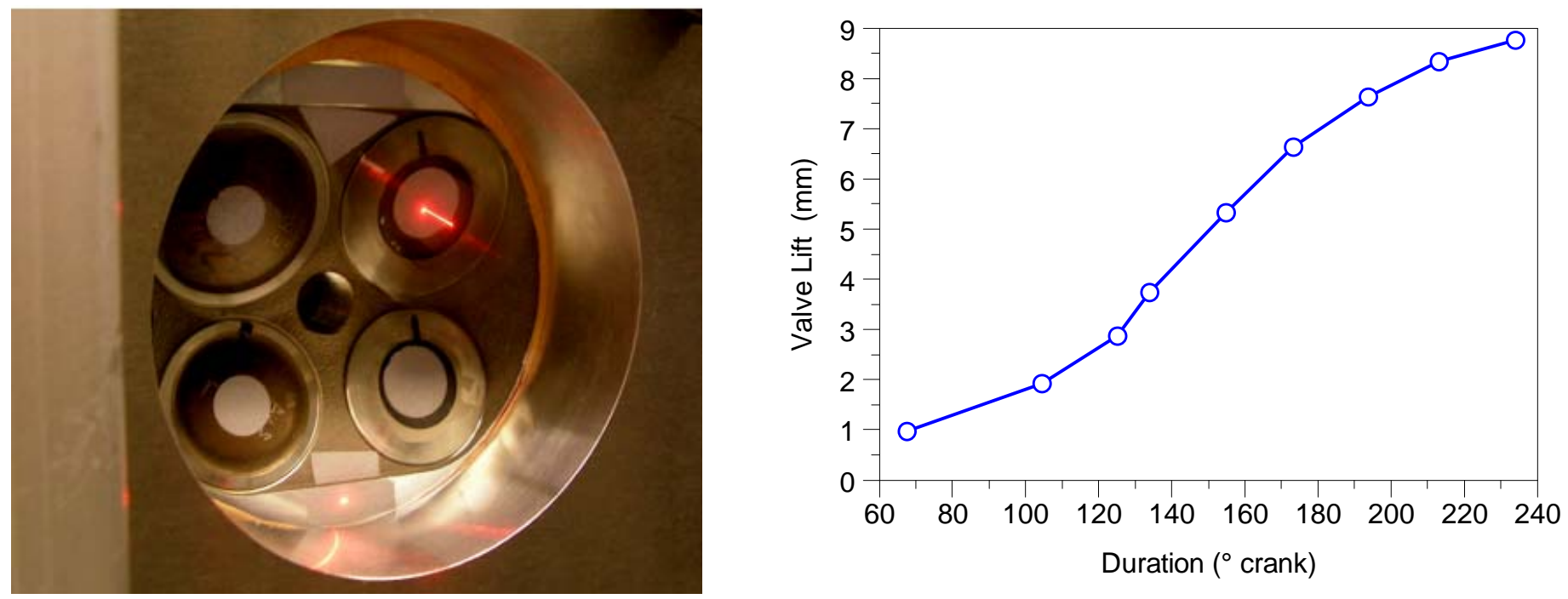

Figure 6: a) Example cylinder head fitted to the valve motion rig with the laser beam directed at one inlet valve and b) inlet valve lift versus duration measurements obtained on a motoring valve motion rig (1500rpm crank)

The valve lift profiles were designed to maintain acceptable dynamic loads at engine speeds up to 6500rpm. Prior to running the test engine, the valve lift versus duration was measured. One set of valves were spot-faced and fitted to the cylinder head sub-assembly. This sub-assembly was itself then fitted to an in-house valve motion measurement rig. In brief, this involved coupling the cylinder head cam drive to an in-line asynchronous electric motor. The head was clamped in-line with the motor using a special mounting plate. A laser differential vibrometer system was then used to obtain direct valve velocity measurements via the laser Doppler interferometry technique, as illustrated in Figure 6(a). The valve durations in this figure and from herein are expressed from end-of-ramp to end-of-ramp as defined by the valve acceleration profiles. The valve lift was estimated via the so-called fringe counting method, with a measurement resolution of $5 \mu \mathrm{m}$. During the tests, the cylinder head oil circuit was connected to an oil conditioning rig that controlled oil temperature and pressure to engine-like motoring conditions $\left(90^{\circ} \mathrm{C} \pm 2^{\circ} \mathrm{C}\right.$, 3bar gauge). The measurements obtained from one inlet valve at 750rpm (1500rpm crank) are illustrated in Figure 6(b). The valve duration is expressed from end-of-ramp to end-of-ramp, determined directly from valve acceleration profiles. In conclusion, such measurements cannot directly account for variation in lift versus crank angle due to firing engine conditions (e.g. torsional vibrations) but were still considered to be acceptable for approximating the valve lift from the known positions of the camshafts and phasers.

\section{FUELS}

Set out in Table 2 are details of key fuel blend components examined during this work. Firstly, a commercial UK pump grade gasoline (“95 RON ULG”) was obtained as a baseline fuel. Samples of iso-octane (“i100”), ethanol (E100) and 1-butanol (Bu100) were also acquired from a chemical supplier, where water content was guaranteed to fall below 100ppm. The iso-octane fuel was tested alone but also used to prepare splash blends of 25\% volume of ethanol (E25i75) and butanol (Bu25i75). A splash blend of 25\% volume ethanol and 75\% volume gasoline (E25g75) was also prepared for comparison. Finally a commercial grade E85 was also 
acquired and an equivalent two-component splash blend of $85 \%$ volume ethanol/15\% volume iso-octane prepared to help compare the effects of higher ethanol content fuels.

\begin{tabular}{|c|c|c|c|c|c|}
\hline & $\begin{array}{c}95 \text { RON } \\
\text { ULG }\end{array}$ & $\begin{array}{c}\mathrm{i} 100 \\
\mathrm{C}_{8} \mathrm{H}_{18} \\
\end{array}$ & $\begin{array}{c}\mathrm{E} 100 \\
\mathrm{C}_{2} \mathrm{H}_{5} \mathrm{OH} \\
\end{array}$ & E85 & $\begin{array}{c}\mathrm{Bu} 100 \\
\mathrm{C}_{4} \mathrm{H}_{9} \mathrm{OH} \\
\end{array}$ \\
\hline $\begin{array}{l}\text { Lower Heating } \\
\text { Value (MJ/kg) }\end{array}$ & 43.2 & 44.2 & 26.6 & 28.9 & 33.2 \\
\hline $\begin{array}{l}\text { Latent Heat } \\
(\mathrm{kJ} / \mathrm{kg})\end{array}$ & - & 305 & 837 & - & 532 \\
\hline RON & 95 & 100 & 110 & 109 & 94 \\
\hline MON & 86 & 100 & 90 & 90 & 80 \\
\hline$(\mathrm{R}+\mathrm{M}) / 2$ & 91 & 100 & 100 & 100 & 87 \\
\hline $\begin{array}{l}\text { Density@15C } \\
\left(\mathrm{g} / \mathrm{m}^{3}\right)\end{array}$ & 0.73 & 0.69 & 0.79 & 0.78 & 0.81 \\
\hline H/C Ratio & 1.90 & 2.25 & 3.00 & 2.66 & 2.50 \\
\hline $\mathrm{O}_{2}$ (\% weight) & 0 & 0 & 35 & 31 & 22 \\
\hline
\end{tabular}

Table 2: Key fuel properties

While "lower" alcohols of reduced carbon count such as methanol and ethanol have previously warranted significant interest, "higher" alcohols such as propanol, butanol and pentanol have also previously been considered for automotive use (32-34). From a thermodynamic stance the higher alcohols generally exhibit higher calorific value (and hence better volumetric fuel consumption), better water tolerance, volatility control and lower Reid vapour pressure. However, benefits in knock resistance and latent heat are typically reduced. Possible differences in source to wheel energy consumption should also be considered if such fuels are ever to be produced on mass but this is highly dependent on the success of future generation biofuel production processes (20).

\section{TEST APPARATUS}

During the tests, the cylinder head was fitted with a Kistler 6041A water-cooled in-cylinder pressure transducer, the face of which was mounted flush with the combustion chamber walls. Pressure data acquisition was performed using a SMETEC Combi system. The corresponding pressure data analysis was performed using AVL Concerto Version 3.8, which included a simple first law heat release analysis. Corresponding thermodynamic parameters were evaluated as the average of values compiled over 300 engine cycles. The engine-out emissions were sampled using a Horiba MEXA 9100 analyser. Fuel flow measurements were performed using a coriolis fuel flow meter assembly, calibrated in-situ to provide a maximum reading error of $<0.5 \%$ at the minimum fuel flow rate examined. 


\section{RESULTS}

\section{EIVC \& VVT EFFECTS (GASOLINE)}

Initially, the effects of EIVC and VVT were investigated using 95 RON ULG fuel. The objective of these first tests was to study EIVC when combined with internal EGR, such as if the engine were to be fitted with a fully variable valvetrain on the inlet and a fixed valvetrain (duration and lift) on the exhaust. These results have been previously reported in full (35) but a summary is still required here to understand the new results. As such, shown in Figure 7 are corresponding maps produced at 1500rpm/3.2bar IMEPn (MBT spark timing, $\lambda=1$ ). This net IMEP was equivalent to that generated in a suitable multi-cylinder production engine at a reference brake load of 2.62bar BMEP (a mapping site used by some OEMs). The "baseline” data point marked on the map indicates the valve timing settings for a typical non-VVT engine, with overlap set to allow acceptable performance across the speed-load map. This valve timing setting falls within the typical window for a nonVVT engine as illustrated in Appendix A. During the experiment, the exhaust valve lift remained locked at the maximum value of $8.9 \mathrm{~mm}$. Initially EVC was also held fixed at $9^{\circ}$ aTDC. The fuel injection timing also remained constant and was set for best fuel economy at the "baseline" condition (EOI=400 $\mathrm{bTDCF}$ ). The most advanced IVO setting shown was governed by valve-to-piston clash, with >1mm clearance maintained.

Shown in the corners of the valve lift map are four valve lift cartoons that help illustrate the valve events occurring in different areas of the map. In the top right-hand corner the engine inlet was throttled, with maximum valve lift and minimum valve overlap applied. In the bottom right-hand corner, IVO was advanced for increased overlap and internal EGR. Moving horizontally from right to left, in the bottom left-hand corner the engine was operating with the highest possible valve overlap and also an unthrottled EIVC strategy. Finally, in the top left-hand corner, the unit was operating with minimum valve overlap and EIVC.

In brief, up to $11 \%$ improvement in net Indicated Specific Fuel Consumption (ISFCn) was possible at this site when combining EIVC and inlet VVT. Of this benefit, 3\% was attributable to VVT as seen in the bottom-right hand corner of the ISFC map. The remaining $~ 8 \%$ was associated with EIVC. It was interesting to note the island of lowest inlet plenum pressure (and worst ISFC) occurred with IVC around $180^{\circ}$. When IVC occurs after $180^{\circ}$, the motion of the piston can push air back up in to the inlet system. When throttled, this resulted in slightly higher inlet plenum pressures and hence marginally lower pumping losses than incurred with IVC at $\sim 180^{\circ}$. The inlet valve duration and lift at the best ISFC site were $112^{\circ} \mathrm{crank} / 2.13 \mathrm{~mm}$. The corresponding standard deviation in gross IMEP ( $\sigma$ IMEP) remained well within acceptable limits (0.06bar).

Page 9 of 24 

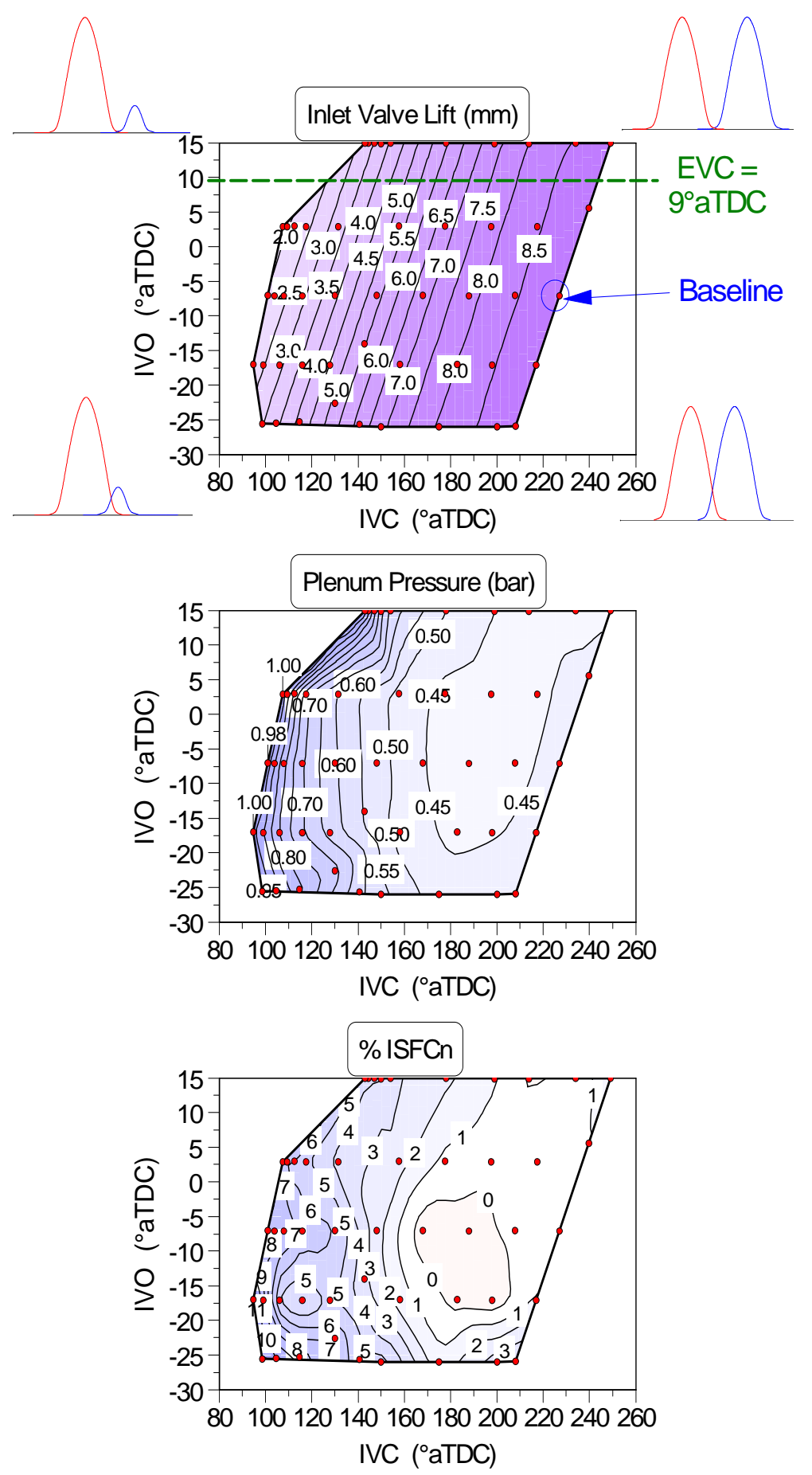

Figure 7: The effects of a fully variable inlet valvetrain at 1500rpm/3.2bar IMEPn (low valve overlap)

Page 10 of 24 

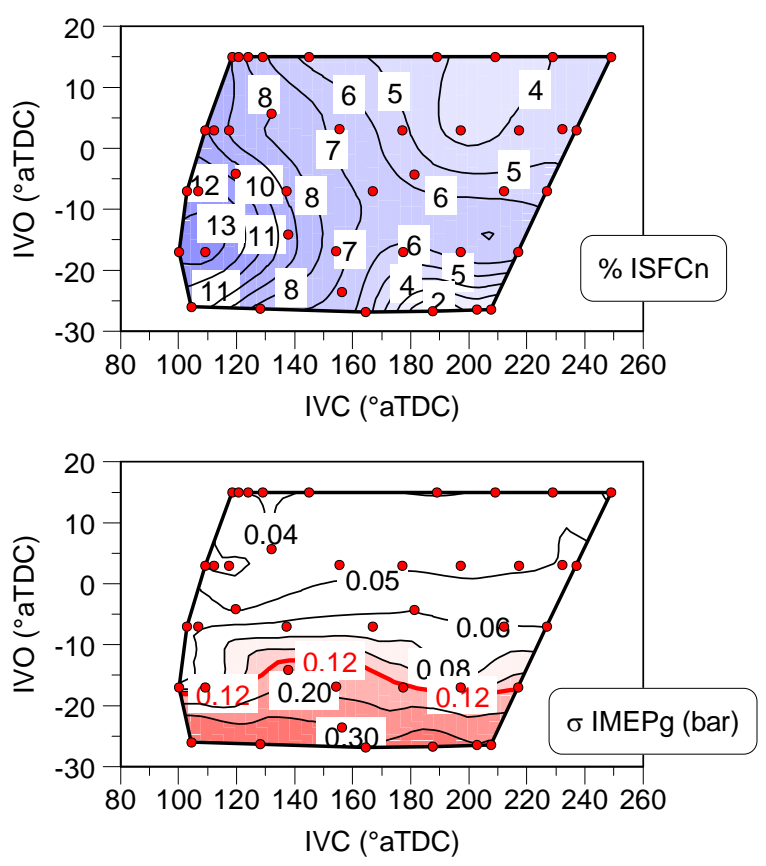

Figure 8: The effects of a fully variable inlet valvetrain at 1500rpm/3.2bar IMEPn (high valve overlap)

The next tests were concerned with combining a fully variable inlet valvetrain with exhaust VVT (a slightly higher cost solution but still feasible). As such, shown in Figure 8 are measurements made at equivalent test conditions to those employed in Figure 7, but now with the exhaust event retarded by $34^{\circ}$ and EVC fixed at $43^{\circ}$ aTDC. An exhaust phase shift of $34^{\circ}$ is well within the capability of typical production cam phasers. Up to $\sim 13 \%$ improvement in fuel economy was now possible c.f. a fixed valvetrain solution, with $\sim 6 \%$ benefit attributed to dual independent VVT and $\sim 7 \%$ associated with throttleless effects. At the site of minimum fuel consumption, the standard deviation in gross IMEP was still only 0.062bar. However, advancing the inlet event beyond this point soon resulted in degradation in stability and hence fuel consumption. The reasons why increasing the valve overlap and mass of internal EGR leads to improved fuel economy when already unthrottled were discussed previously (35) and were largely attributed to higher valve lifts and reduced throttling at the inlet valve itself and reduced peak heat transfer rates. In this previous work it was concluded the more EGR tolerated the better.

\section{ALCOHOL EFFECTS (LOW VALVE OVERLAP)}

The purpose of these tests was to establish how the current fuel blends behaved during inlet cam VLD phaser sweeps with the valve timing maintained in the baseline low overlap condition. Shown in Figure 9 are key measurements during such sweeps from throttled to full unthrottled operation at 1500rpm/3.2bar IMEPn. Set out in Table 3 is corresponding data at the end of each sweep when unthrottled, with the inlet plenum pressure at 1.0bar (+0, -0.01 bar). During the experiments the end of injection remained fixed at $400^{\circ} \mathrm{bTDC}$, with $\lambda=1.0$. The spark was optimised to MBT timing at all logged sites. Some small differences in inlet plenum pressure were observed at the start of the sweeps but these have been attributed to fluctuations in ambient temperature rather than any notable trend due to differences in latent heat at the relatively low fuel flow rates examined. 


\begin{tabular}{|c|c|c|c|c|c|}
\hline Fuel & $\begin{array}{c}\text { Inlet } \\
\text { duration } \\
\left({ }^{\circ} \mathbf{c} \text {.a.) }\right.\end{array}$ & Lift (mm) & $\eta_{\text {GE }} \mathbf{( \% )}$ & $\eta_{\mathbf{T}}$ (\%) & $\sigma$ IMEP (bar) \\
\hline $\begin{array}{c}\text { 95 RON } \\
\text { ULG }\end{array}$ & 108.0 & 2.04 & 87.5 & 34.1 & 0.029 \\
\hline i100 & 107.2 & 2.0 & 87.0 & 34.5 & 0.039 \\
\hline Bu25i75 & 107.3 & 2.0 & 87.2 & - & 0.035 \\
\hline E25i75 & 107.7 & 2.02 & 87.6 & - & 0.035 \\
\hline E25g75 & 107.5 & 2.01 & 87.6 & - & 0.037 \\
\hline E85i15 & 107.6 & 2.01 & 87.6 & 34.5 & 0.040 \\
\hline E85g15 & 107.4 & 2.0 & 87.0 & 34.5 & 0.050 \\
\hline E100 & 107.5 & 2.01 & 87.0 & -042 \\
\hline
\end{tabular}

Table 3: Key parameters when fully unthrottled during the low valve overlap tests (1500rpm/3.2bar IMEPn)
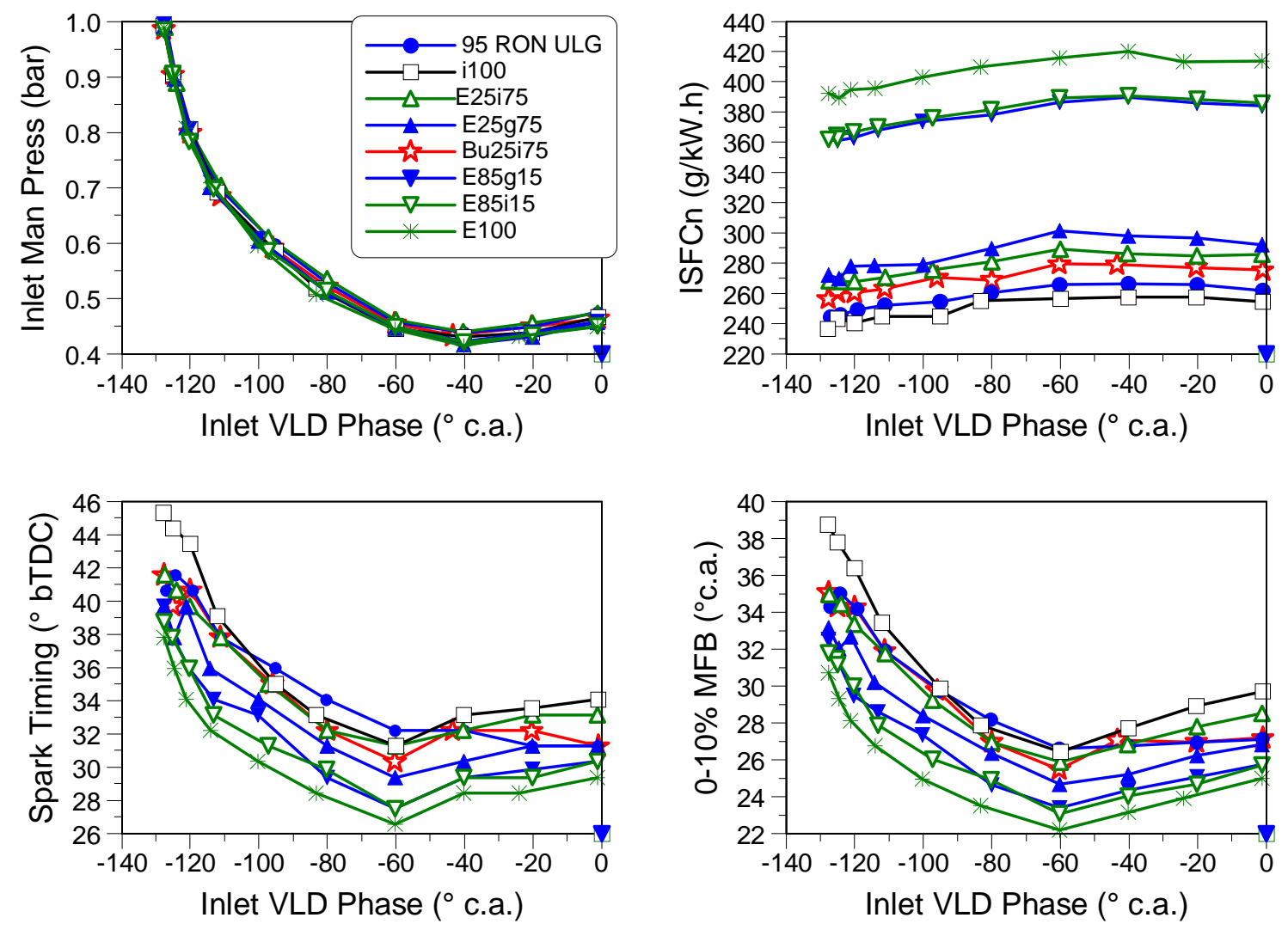

Figure 9: Key performance measurements during the low valve overlap tests (1500rpm/3.2bar IMEPn) Page 12 of 24 
Considering fuel consumption, the calorific value of the gasoline was $\sim 49 \%$ higher than the commercial E85, with the E85 then incurring a $\sim 46 \%$ increase in mass fuel consumption when throttled at this site. Some small benefits were noted with the alcohol blends that must have partially offset such calorific deficit. The high ethanol content fuels exhibited slightly higher values of thermal efficiency $(<0.4 \%)$, which could have been partly associated with higher $\mathrm{H} / \mathrm{C}$ ratio and ratio of specific heats c.f. the non-oxygenated baselines. The influence of faster rates of mass burning on thermal efficiency must also be considered. The spark timing and mass fraction burned data indicated that the higher ethanol content blends burned faster under both throttled and unthrottled conditions. This observation is in good agreement with laminar burning velocity correlations in the literature $(36,37)$ and also recent observations by the currently reporting authors in a modern multi-cylinder turbocharged DI SI engine (27). Otherwise, the iso-octane incurred marginally lower indicated fuel consumption than the commercial gasoline case. Again, this may have been attributable to the higher calorific value and greater $\mathrm{H} / \mathrm{C}$ ratio of this single component fuel. This benefit remained apparent when comparing the two $25 \%$ ethanol cases but was not evident when the volume of ethanol was increased to $85 \%$. Finally, the butanol blend would be expected to incur lower ISFC than its ethanol equivalent due to being matched on a volume basis and hence incurring lower oxygen mass content and higher calorific value. However, overall it is important to note the inherent error margin within the calorific value measurement method $(+/-0.7 \mathrm{MJ} / \mathrm{kg})$

All of the fuels tested required remarkably similar inlet valve duration/lift settings, with differences within typical control limits of a hydraulic cam phaser $\left(<1^{\circ}\right.$ c.a.). In turn, the gas exchange efficiencies $\left(\eta_{\mathrm{GE}}\right.$, the ratio of net to gross IMEP) were very similar and within $0.6 \%$ efficiency. Such similar duration/lift settings indicate that a flex-fuelled engine employing EIVC for unthrottled load control may only require a standard gasoline calibration for acceptable operation with all such blends. However, this observation neglects VVT effects and also the impact of varied speed and load, discussed later. The standard deviation in gross IMEP was below 0.06 with all fuels, indicating increased valve overlap could be tolerated in all cases.

Shown in Figure 10 are corresponding engine-out emissions for the two-component blends. The values of NOx are in good agreement with previous accounts of reduced adiabatic flame temperatures with such alcohol fuels (32-34). However, high values of engine-out CO were observed with butanol, which perhaps indicates a more complicated interaction than just differences in peak gas temperatures. Variation in mixture homogeneity cannot be discounted but was unexpected given the early port injection on to the back of the warm closed valves.

One common problem with oxygenated fuel hydrocarbon emissions measurement is reduced response of the Flame Ionisation Detector if calibrated using non-oxygenated gases. Therefore, as well as raw measurements, also shown in Figure 10 are corrected values of hydrocarbons based on a method proposed by Dec et al. (38). In brief, this method involves attempting to correct for the lack of response of the FID to oxygenated hydrocarbons by accounting for the "missing carbon" in the exhaust relative to that in the incoming fuel. Caution is required when employing this method due to the need for extremely high accuracy in fuel flow measurement and only the high alcohol content data has been corrected given this uncertainty. Nonetheless, after correction it still appeared that the pure ethanol fuel enabled significant engine-out hydrocarbon emissions reductions compared to gasoline fuel under both throttled and unthrottled conditions (albeit with the relative benefit reduced from $\sim 50 \%$ to $\sim 26 \%$ when throttleless).

Page 13 of 24 

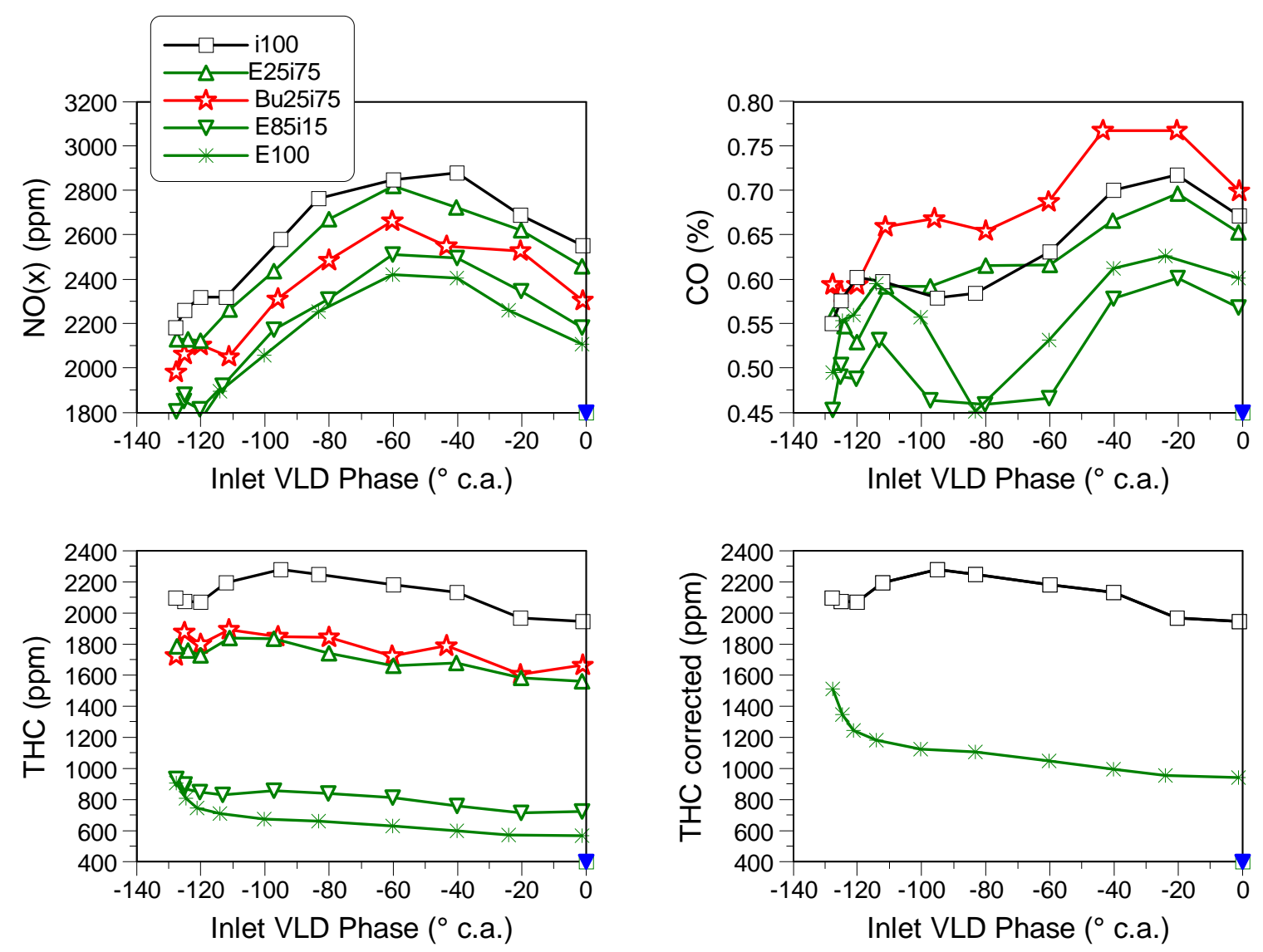

Figure 10: Emissions measurements during VLD phaser sweeps with fixed low valve overlap (1500rpm/3.2bar IMEPn)

\section{ALCOHOL EFFECTS (HIGH VALVE OVERLAP)}

The purpose of these tests was to establish the behaviour of the fuels during EIVC operation when combined with VVT, as per an engine equipped with a fully variable valvetrain on the inlet and independent VVT on the exhaust. During previous work with gasoline fuel (35) it was demonstrated that such a strategy reduced the throttling at the inlet valve itself, with increased EGR allowing higher valve durations and lifts to be used. This was associated with increased inlet valve lift-to-duration ratio, with operation nearer to the point of inflection on the S-shaped valve lift curve introduced in Figure 8. During this earlier work, summarised above in Figures 7 and 8, internal EGR was increased using a retarded high valve overlap strategy (with the centreline of the overlap event occurring sometime after TDC and EGR also being drawn back in to the cylinder) by first retarding the exhaust to its end stop before advancing the inlet valve timing. During previous multi-cylinder work (4), the current authors also demonstrated that such a retarded overlap strategy may improve combustion stability for a given fuel consumption benefit, at least under conventional throttled conditions. However, here it was decided to employ more advanced high overlap, which is a common strategy used in production. Furthermore, this new work then allowed some comparison of advanced and retarded overlap during EIVC. Again, throughout these new tests MBT spark timing, EOI $=400^{\circ}$ and $\lambda=1.0$ fuelling were maintained. The valve overlap settings used in each sweep are listed in Table 4 and were chosen so that the acceptable combustion stability limit $(\sigma \mathrm{IMEPg}<0.12)$ was being approached when unthrottled.

Page 14 of 24 


\begin{tabular}{|c|c|c|c|c|c|}
\hline Fuel & $\begin{array}{c}\text { EVC } \\
\left({ }^{\circ} \mathbf{b T D C}\right)\end{array}$ & IVO ( $\left.{ }^{\circ} \mathbf{a T D C}\right)$ & Overlap ( $\left.{ }^{\circ} \mathbf{C . a .}\right)$ & $\begin{array}{c}\text { Inlet duration } \\
\left({ }^{\circ} \mathbf{c . a .}\right)\end{array}$ & Lift (mm) \\
\hline $\begin{array}{c}\text { 95 RON } \\
\text { ULG }\end{array}$ & -30.5 & -26 & 56.5 & 118.6 & 2.61 \\
\hline i100 & -23.5 & -26 & 49.5 & 116.5 & 2.48 \\
\hline Bu25i75 & -31.5 & -26 & 57.5 & 119.4 & 2.66 \\
\hline E25i75 & -30.5 & -26 & 56.5 & 118.0 & 2.58 \\
\hline E85g15 & -33.5 & -26 & 59.5 & 124.4 & 2.97 \\
\hline E100 & -35.5 & -26 & 61.5 & 123.6 & 2.93 \\
\hline
\end{tabular}

Table 4: Valve settings during the high overlap tests (1500rpm/3.2bar IMEPn)

Shown in Figure 11 are selected results obtained with key blends. Firstly, it was interesting to note the "bump" in $\sigma \mathrm{IMEPg}$ as unthrottled mode was approached. During full unthrottled operation, the exhaust-to-inlet manifold EGR pressure ratio was at its lowest. Conversely, the throttling at the inlet valve itself was at its highest and this is indicated in the values of rate of change of intake plenum pressure versus crank angle $(\mathrm{dp} / \mathrm{d} \alpha)$. Looking from left to right across the figures, as the intake throttle began to close the rate of increase in EGR pressure ratio was at its highest, while throttling at the valve itself must have remained significant under the reduced lift conditions still being employed. During such a transition it seems plausible that the engine will inhale more EGR than when fully unthrottled, which leads to deterioration in combustion stability (fairly rapidly given the engine is already near the stability limit). This effect arguably seems evident in the emissions, with sudden reduction in NOx and increase in $0-10 \%$ MFB as the intake throttle was initially closed. The event was also apparent in the three-dimensional map of combustion stability previously introduced in Figure 8 . From the work of others (8), as the inlet duration is prolonged further the in-cylinder turbulence levels at ignition should increase and presumably help overcome these effects.

Shown in Table 5 is a comparison of the percentage improvement in ISFCn with three valve operating strategies; namely 1) VVT, 2) EIVC (baseline overlap) and 3) EIVC+VVT. All \% values are expressed relative to baseline operation (throttled, non-VVT). The cam timings used in both VVT cases were equivalent for any given fuel and set to maintain acceptable combustion stability when fully unthrottled during the EIVC+VVT cases. The gas exchange efficiency and stability is also presented for the EIVC+VVT mode. Clearly, the VVT case does not represent the maximum fuel economy benefit available via such technology alone. Rather, the data demonstrates the potential fuel savings if the VVT remained locked during a stable transition from EIVC to throttled operation. In Figure 10, it was shown that up to 6\% improvement in fuel economy could be obtained at this site via VVT alone with a high retarded overlap strategy. Another point to note in the new data is lack of improvement in fuel consumption when adopting VVT in addition to EIVC with the gasoline fuel. Again, the previous retarded high overlap approach allowed an additional $~ 5 \%$ improvement to be obtained c.f. EIVC alone. Valve overlap phase sweeps should be performed in future work to clarify these effects but it appears that a retarded high overlap strategy may allow greater fuel savings when combining VVT with EIVC. That said, some caution is generally required given a single cylinder engine was being used, with potential cylinder-tocylinder interactions and associated manifold tuning effects omitted. 
Otherwise, the data in both Figure 11 and Table 5 suggested that higher alcohol content fuels enabled improved EGR tolerance and hence the greatest relative fuel savings. The gasoline, E85g15 and E100 cases can all be compared in a quantitative manner given equivalent $\sigma$ IMEPg was achieved. The inlet plenum pressures at the start of each sweep showed good agreement with the degree of valve overlap employed. The mechanisms behind improved fuel consumption are also indicated in the pressure-volume diagram in Figure 12, which shows the mean pressure data for the E85g15 baseline, EIVC and EIVC+VVT cases. In summary, compared to EIVC alone, the addition of VVT allowed increased expansion work and reduced pumping losses (again associated with reduced throttling at the inlet valves). Differences in heat transfer with increased EGR should also not be discounted. Otherwise, in terms of fuel effects, the E100 values of corrected unburned hydrocarbons were $\sim 40 \%$ and $\sim 46 \%$ lower than the gasoline throttled and unthrottled cases respectively. The iso-octane was the worst performer in terms of EGR tolerance and this may be partly associated with the lower laminar burning velocity of this fuel.
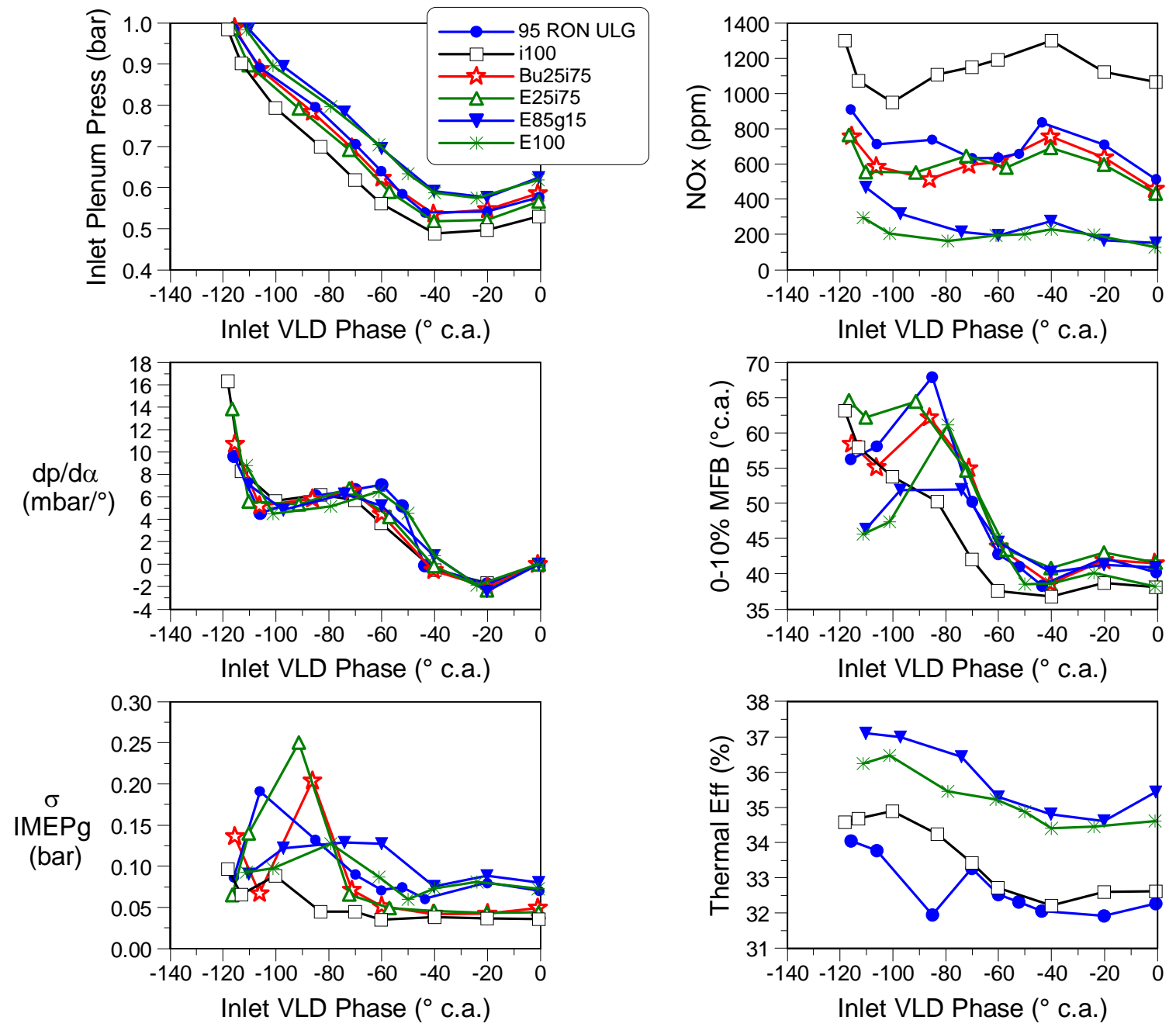

Figure 11: Key measurements during sweeps from throttled to unthrottled operation with high valve overlap (1500rpm/3.2bar IMEPn) 


\begin{tabular}{|l|c|c|c|c|c|}
\hline & \multicolumn{3}{|c|}{ \% ISFC } & $\eta_{\text {GE }}$ (\%) & $\sigma$ IMEP (bar) \\
\hline & VVT & EIVC & VVT+EIVC & VVT+EIVC & VVT+EIVC \\
\hline 95RON & 1.26 & 6.5 & 6.7 & 88.8 & 0.09 \\
\hline i100 & 1.82 & 7.0 & 7.4 & 88.4 & 0.10 \\
\hline Bu25i75 & 3.7 & 6.9 & 8.6 & 88.3 & 0.14 \\
\hline E25i75 & 3.9 & 6.9 & 9.4 & 88.8 & 0.07 \\
\hline E25g75 & 3.0 & 6.9 & 9.5 & 89.5 & 0.09 \\
\hline E85g15 & 8.4 & 6.1 & 12.5 & 89.6 & 0.09 \\
\hline E100 & 5.5 & 5.2 & 9.7 & 88.5 & 0.09 \\
\hline
\end{tabular}

Table 5: Comparison of ISFCn's during VVT, EIVC and VVT+EIVC operation (1500rpm/3.2bar IMEPn)

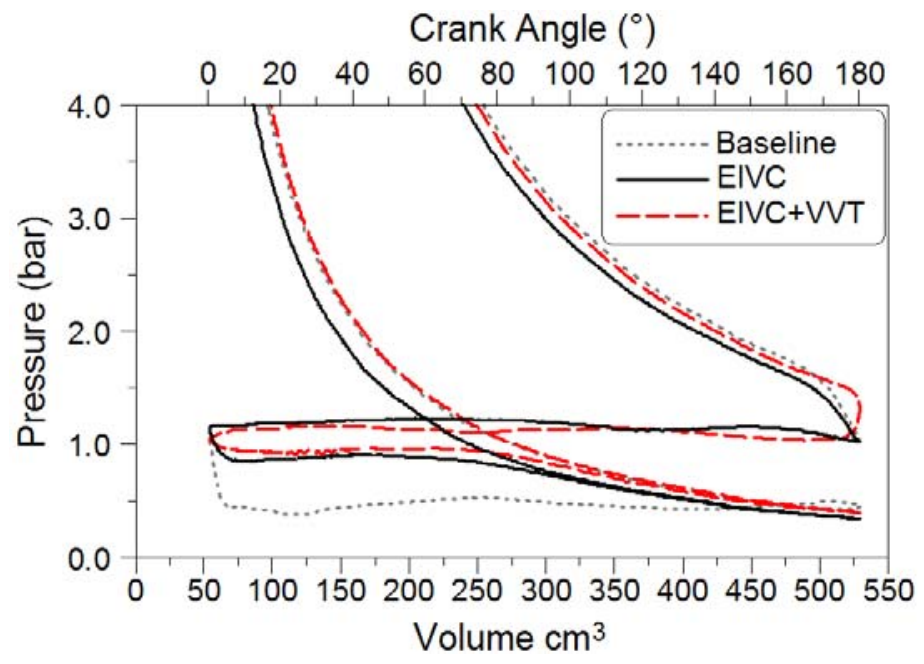

Figure 12: Section of a p-V diagram showing differences in expansion and pumping for the different valve operating strategies with E85g15 fuel

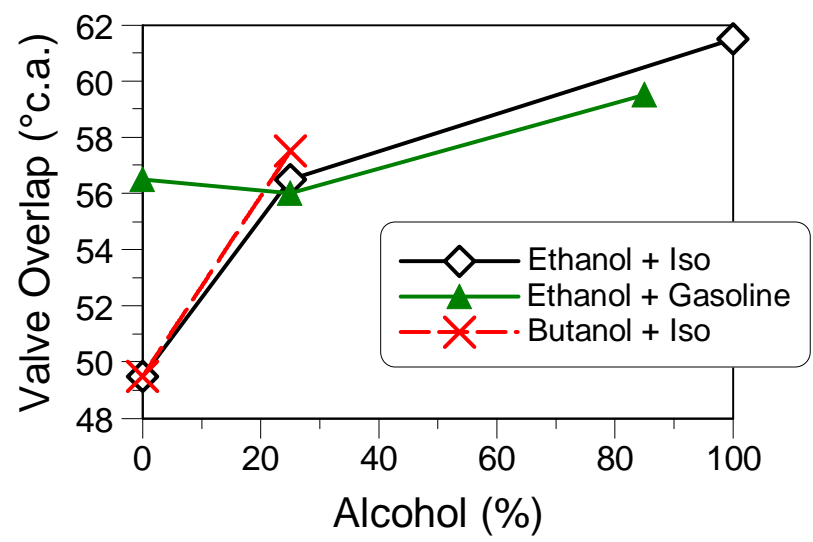

Figure 13: Valve overlap tolerated versus alcohol content (1500rpm/3.2bar IMEPn)

Page 17 of 24 
In summary, the current results indicated that the adoption of faster burning fuels may extend the EGR tolerance of the engine. Detailed optical work and in-depth thermodynamic analysis is ideally required in future work to establish if this is due to reduced flame stretch and/or other mechanism(s). Small differences in the flow field at the different valve settings employed cannot be discounted. A final important factor to consider in terms of calibration is the linearity of the valve overlap tolerated with increasing alcohol content. As such, set out in Figure 13 are corresponding values for key blends. In summary, the pure iso-octane fuel appeared to be something of an outlier, with relatively poor EGR tolerance apparent in both the low overlap setting achieved and high engine-out NOx recorded. It was interesting to note that no significant increase in overlap was noted with E25g75 fuel c.f. the gasoline baseline. Otherwise the two E25 cases were remarkably similar in terms of overlap. Overall it can be concluded that higher alcohol content was required to claim any reasonable increase in overlap. Such linearity checks should be repeated in future work at additional sites.

\section{SPEED-LOAD EFFECTS}

The above results indicated that high ethanol fuels exhibited improved EGR tolerance, which warranted reoptimisation of fully variable inlet valve settings during unthrottled engine operation. In order to verify that no other effects would arise under typical part-load conditions, the low valve overlap EIVC tests were repeated but at a variety of speed-load sites. Detailed maps were already available for the gasoline fuel. Therefore, in the current work it was decided to return to key sites but using the commercial E85 fuel. During all tests the inlet plenum pressure was again controlled to 1.0bar (+0,-0.01). Again, at all sites the spark timing was set for MBT, with stoichiometric fuelling and $\mathrm{EOI}=400^{\circ} \mathrm{bTDC}$ also maintained.

Set out in Figure 14 are the values of inlet valve lift required when operating with an EIVC strategy using gasoline fuel. Reasonable variation in lift was necessary in order to apply full unthrottled mode over such a window and, as was shown previously (35), this variation increases further when VVT can also be used. The lowest load mapped with EIVC alone was equivalent to that in a multi-cylinder engine when idling (warm). Under such conditions the $0-10 \%$ mass fraction burned period was observed to increase significantly c.f. baseline throttled operation, prolonged by $15^{\circ} \mathrm{C}$.a. or $35^{\circ} \mathrm{c}$.a. at $850 \mathrm{rpm}$ or $2000 \mathrm{rpm}$ respectively. This was presumably due to reduced turbulence intensity at ignition. In fact, the combustion stability was already borderline at 2000rpm and consequently it was not possible to increase the valve overlap at all at this site. However, it is important to note that the cylinder head used throughout this work did not include combustion chamber masking and was of relatively low tumble ratio, as described previously (35). Regardless, the current hardware was still considered acceptable to study fuel effects. Also shown in Figure 14 are the corresponding maps of percent improvement in ISFC relative to non-VVT operation, with the benefit varying from 4-10\% predominantly with engine load. The percentage benefit appeared to be reasonably similar with each fuel.

Also set out in Figure 14 is the difference in inlet valve duration when operating on the commercial E85 fuel, where a positive value denotes a longer duration c.f. gasoline. In summary, up to $3^{\circ} \mathrm{C}$.a. reduction in duration was observed at higher speeds and low loads. This variation may have been the result of the faster burning of the E85 fuel helping to overcome the onset of unstable combustion at higher speeds and lower loads. For example, the $0-10 \% \mathrm{MFB}$ at $2000 \mathrm{rpm} / 1.85 \mathrm{bar}$ was $53^{\circ} \mathrm{c}$.f. $70^{\circ} \mathrm{C}$.a. using gasoline. The corresponding values of бIMEPg were 0.06 and 0.15 respectively. Another factor to consider was marginally lower expansion and exhaust pressures with E85 and hence changes in internal EGR but this would be hard to quantify without detailed thermodynamic modelling and/or direct EGR measurement. Reduced iEGR would be in good agreement with shorter duration being required but otherwise cannot be substantiated. Regardless, of this $3^{\circ} \mathrm{c}$.a. variation, $1-2^{\circ}$ c.a. fluctuation might be encountered during normal engine operation due to the control of a 
hydraulic cam phaser. Furthermore, the difference in gas exchange efficiency at each site was within $0.5 \%$ (efficiency difference) c.f. gasoline. It has therefore been concluded that, over the limited window studied, the conclusion of variation in EGR tolerance being the dominant factor when adding alcohol to a gasoline engine using EIVC at part-load is correct. Future work should also therefore be concerned with the application of EIVC at higher loads both with and without VVT to help establish the variation in valve lift/duration with such fuels when differences in latent heat may become more profound. Whether such fluctuation in VLD phase can be tolerated in production remains to be seen; if not then electrically controlled cam phasers may offer an improved technical solution.
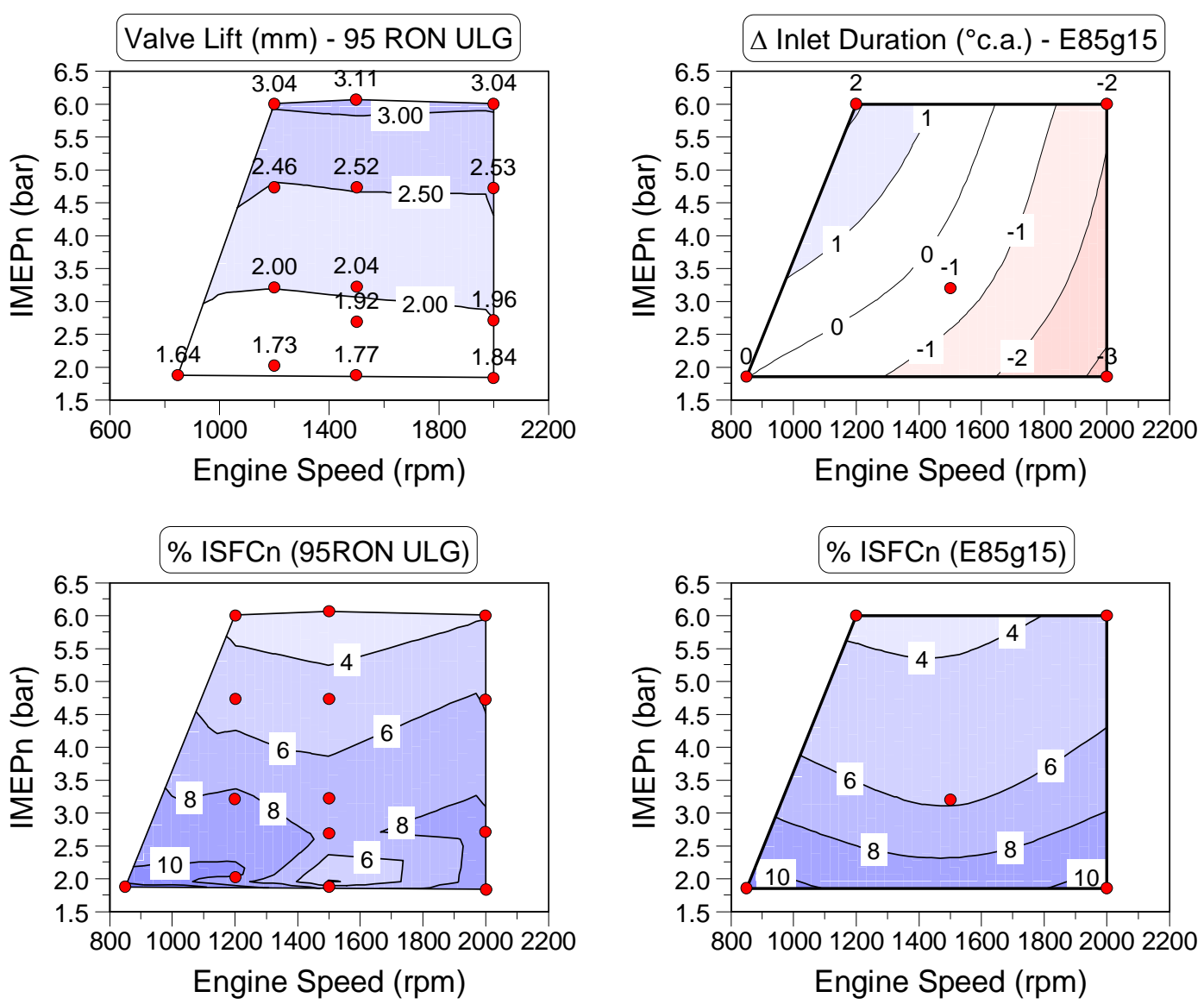

Figure 14: EIVC speed-load maps for the 95 RON ULG and E85g15 fuels

\section{CONCLUSIONS}

The effects of combining EIVC with internal EGR were studied during port fuel injection of various alcohol blended fuels in a thermodynamic single cylinder research engine. Under fixed low valve overlap conditions at a typical cruising site of 1500rpm/3.2bar IMEPn the following conclusions were made:

- The wide range of fuels tested required remarkably similar inlet valve duration and lift values when operating fully unthrottled with low valve overlap. In turn, peak gas exchange efficiencies were all within $0.6 \%$ efficiency. 
- The high ethanol content fuels enabled small improvements in thermal efficiency of up to $0.4 \%$ efficiency c.f. gasoline.

- One known problem of EIVC operation is increased engine-out hydrocarbon emissions. During these experiments, the high ethanol content fuels incurred up to $~ 50 \%$ lower (corrected) hydrocarbon emissions c.f. pure iso-octane.

The low valve overlap experiments were repeated across a typical part-load operating window and the additional conclusions made:

- When using gasoline fuel, EIVC resulted in degradation in combustion stability at lower loads, especially at higher speeds. This degradation was associated with prolonged combustion duration and presumably reduced turbulence intensities at ignition.

- High ethanol content fuel helped to overcome these effects, with faster rates of mass burning at all visited sites.

- At the highest speed and lowest load studied during EIVC operation with commercial E85, the difference in inlet VLD cam phaser setting c.f. gasoline was at its highest level ( $\left.3^{\circ} \mathrm{crank}\right)$.

During high valve overlap conditions at the same 1500rpm part-load site, the following conclusions were also apparent:

- The pure iso-octane was a poor baseline fuel relative to gasoline for these experiments, tolerating relatively low internal EGR. This observation needs to be verified but may have significant repercussions as this fuel is often used as a substitute for gasoline, especially during optical experiments where reduced window fouling is desired.

- The high ethanol content fuels enabled improved EGR tolerance and increased valve overlap settings. This observation may be in good agreement with measurements of higher laminar burning velocity for such fuels under stoichiometric conditions.

- In turn, when combining EIVC and VVT the improved EGR tolerance of the high ethanol fuels enabled later EVO, increased expansion work and reduced throttling at the inlet valve itself. In turn, additional relative fuel consumption benefits of up to $\sim 3 \%$ were possible c.f. gasoline.

In summary it would appear that high ethanol content fuels exhibit strong synergy with combined EIVC/VVT operation. Under such conditions, a (relatively) advanced VVT strategy appeared to be less favourable than retarded high overlap. This seems to be in agreement with observations made in other engines during throttled operation but additional work is required to better understand these effects when unthrottled. Future research should also be concerned with the influence of combustion chamber masks when operating in such throttleless modes with PFI and/or DI of such fuels.

\section{REFERENCES}

1. Kramer, U. and Phlips, P.: "Phasing Strategy for An Engine With Twin Variable Cam Timing”, SAE Paper No. 2002-01-1101, (2002).

Page 20 of 24 
2. Moro, D., Minelli, G. and Serra, G.: "Thermodynamic Analysis of Variable Valve Timing Influence on SI Engine Efficiency”, SAE Paper No. 2001-01-0667, (2001).

3. Roberts, C.E. and Stanglmaier, R.H.: "Investigation of Intake Timing Effects on the Cold Start Behaviour of a Spark Ignition Engine”, SAE Paper No. 1999-01-3622, (1999).

4. Cairns, A., Irlam, G. and Blaxill, H.: "Exhaust Gas Recirculation for Improved Part and Full Load Fuel Economy in a Turbocharged Gasoline Engine”, SAE Paper No. 2006-01-0047, (2006).

5. Schäfer, J. and Balko, J.: "High Performance Electric Camshaft Phasing System”, SAE Paper No. 2007-011294, (2007).

6. Tuttle, J.: “Controlling engine load by means of Late Intake Valve Closing”, SAE Paper No. 800794, (1980).

7. Tuttle, J.: “Controlling engine load by means of Early Intake Valve Closing”, SAE Paper No. 820408, (1982).

8. Cleary D., Silvas G.: “Unthrottled Engine Operation with Variable Intake Valve Lift, Duration and Timing”, SAE Paper No. 2007-01-1282, (2007).

9. Hannibal, W., Flierl, R., Stiegler, L. and Meyer, R.: “Overview of Current Continuously Variable Valve Lift Systems for Four-Stroke Spark-Ignition Engines and the Criteria for their Design Ratings”, SAE Paper No. 2004-01-1263, (2004).

10. Sauer, C., Kulzer, A., Rauscher, M. and Hettinger, A.: “Analysis of Different Gasoline Combustion Concepts with Focus on Gas Exchange”, SAE Paper No. 2008-01-0427, (2008).

11. Allen, J. and Law, D.: “Advanced Combustion Using a Lotus Active Valve Train: Internal Exhaust Gas Recirculation Promoted Auto-Ignition”, Proceedings of the IFP International Congress 2001, p.p. 85-100, (2001).

12. Koopmans, L., Strom, H., Lundgren, S., Backlund, O. and Denbratt, I.: “Demonstrating a SI-HCCI-SI Mode Change on a Volvo 5-Cylinder Electronic Valve Control Engine”, SAE Paper No. 2003-01-0753, (2003).

13. Unger, H., Schneider, J., Schwarz, C. and Kock, K-F., "VALVETRONIC - Experience from 7 years of Series Production and a Look into the Future”, 29. International Wiener Motorensymposium, (2008).

14. Shimizu, K., Fuwa, N., Yoshihara, Y. and Hori, K.: “ The New Toyota variable Valve Timing and Lift System”, Aachener Kolloquium Fahrzeug und Motorentechnik, (2007).

15. Tsuruta, S.: "The Innovative Variable Valve Event and Lift System (VVEL) for the New Nissan V6 and V8 Engine”, 29. International Wiener Motorensymposium, (2008).

16. Fujita, T., Onogawa, K., Kiga, S., Mae, Y., Akasaka, Y. and Tomogane, K.: “Development of Innovative Variable Valve Event and Lift (VVEL) System”, SAE Paper No. 2008-01-1349, (2008).

17. Sellnau, M., Kunz, T., Sinnamon, J. and Burkhard, J.: "2-step Variable Valve Actuation: System Optimisation and Integration on an SI Engine”, SAE Paper No. 2006-01-0040, (2006).

18. Stansfield P.A., Wigley G., Garner C.P., Patel R., Ladommatos N., Pitcher G., Turner J.W.G., Nuglisch H., Helie J.: "Unthrottled Engine Operation using Variable Valve Actuation: The Impact on the Flow Field, Mixing and Combustion”, SAE Paper No. 2007-01-1414, (2007).

19. Patel, R., Ladommatos, N., Stansfield, P., Wigley, G., Garner, P., Pitcher, G., Turner, J.W.G. and Nuglisch, H.: "Comparison between Unthrottled, Single and Two-valve Induction Strategies Utilising Direct Gasoline Injection: Emissions, Heat-release and Fuel Consumption Analysis”, SAE Paper No. 2008-01-1626, (2008).

20. Dohmel, K.: "Future Mobility from a Fuels Perspective", 29 Internationales Wiener Motorensymposium, (2008).

21. Bergström, K., Melin, S-A. and Jones, C.: “The New ECOTEC Turbo BioPower Engine from GM Powertrain - Utilising the Power of Nature's Resources”, 28 Internationales Wiener Motorensymposium, (2007).

22. Kapus, P., Fuerhapter, A., Fuchs, H. and Fraidl, G.K.: "Ethanol Direct Injection on Turbocharged SI Engines - Potential and Challenges”, SAE Paper No. 2007-01-1408, (2007).

23. Brewster, S.: "Initial Development of a Turbocharged Direct Injection E100 Combustion System”, SAE Paper No. 2007-01-3625, (2007).

24. Kremer, F.G. and Fachetti, A.: “Alcohol as Automotive Fuel - Brazilian Experience”, SAE Paper No. 200001-1965, (2000).

25. Turner, J.W.G., Pearson, R.J., Holland, B. and Peck, A.: "Development of a High Performance Sports Car for Operation on a High Alcohol-Blend Fuel”, JSAE Paper No. 20075038, (2007).

26. Brusstar, M., Stuhldreher, M., Swain, D. and Pidgeon, W.: "High Efficiency and Low Emissions from a Port Injected Engine with Neat Alcohol Fuels”, SAE Paper No. 2002-01-2743, (2002).

Page 21 of 24 
27. Cairns, A., Stansfield, P., Fraser, N. and Blaxill, H.: “A Study of Gasoline-Alcohol Blended Fuels in an Advanced Turbocharged DISI Engine”, SAE Paper No. 2009-01-0138, (2009).

28. Malcolm, J.S., Aleiferis, P.G., Todd, A.R., Cairns, A., Hume, A., Blaxill, H., Hoffmann, H. and Rueckauf, J.: “A Study of Alcohol Blended Fuels in a New Optical Spark Ignition Engine”, IMechE Performance, Fuel Economy and Emissions Conference, London, (2007).

29. Malcolm, J.S., Aleiferis, P.G., Todd, A.R., Cairns, A., Hoffmann, H.: “An Optical Study of Spray Development and Combustion of Ethanol, Iso-Octane and gasoline Blends in a DISI Engine”, SAE Paper No. 2008-01-0073, (2008).

30. Lancefield, T., Lawrence, T., Ahmed, A. and Hamouda, H.B.H.: "VLD - A flexible, modular, cam operated VVA system giving variable valve lift and duration and controlled secondary valve openings", SIA Conference on Variable Valve Actuation, IFP Rueil, (2006).

31. Bunsen, E., Grote, A., Willand, J., Hoffmann, H., Fritz, O. and Senjic, S.: "Fuel consumption improvements by variation of intake valve lift and timing - A mechanically fully variable valvetrain system for a $1.6 \mathrm{l}$ gasoline engine with direct injection”, Haus der Technik Variable Valvetrain Congress, (2007).

32. Gautam, M. and Martin, D.W.: "Combustion Characteristics of Higher Alcohol/Gasoline Blends", Proc Instn Mech Engrs Vol 214 Part A, (2000).

33. Yacoub, Y., Bata, R. and Gautam, M.: "The Performance and Emission Characteristics of $\mathrm{C}_{1}-\mathrm{C}_{5} \mathrm{Alcohol-}$ Gasoline Blends with Matched Oxygen Content in a Single Cylinder Spark Ignition Engine”, Proc Instn Mech Engrs Vol 212 Part A, (1998).

34. Bata, R.M., Elrod, C. and Lewandowski, T.P.: "Butanol as a Blending Agent for I.C. Engines”, SAE Paper No. 890434, (1989).

35. Cairns, A., Todd, A., Hoffman, H., Aleiferis, P. and Malcolm, J.: "Combining Unthrottled Operation with Internal EGR Under Port and Central Direct Fuel Injection Conditions in a Single Cylinder SI Engine”, SAE Paper No. 2009-01-1835, (2009).

36. Gülder, Ö.L., "Burning Velocities of Ethanol-Isooctane Blends”, Combustion and Flame, Vol. 56, pp. 261168, 1984.

37. Beeckmann, J., Rohl, O. and Peters, N.: "Experimental and Numerical Investigation of Iso-octane, Methanol and Ethanol Regarding Laminar Burning Velocity at Elevated Pressure and Temperature”, SAE Paper No. 2009-01-1774, (2009).

38. Dec, J.E., Davisson, M.L., Sjöberg, M., Leif, R.N. and Hwang, W.: “Detailed HCCI Exhaust Speciation and the Sources of Hydrocarbon and Oxygenated Hydrocarbon Emissions”, SAE Paper No. 2008-01-0053, (2008).

\section{CONTACT INFORMATION}

Neil Fraser, MAHLE Powertrain Ltd., Costin House, St. James Mill Rd., Northampton, NN5 5TZ, U.K. Tel: +44(0)870 157 3133, Fax: +44(0)870 157 3100, Email: neil.fraser@gb.mahle.com

\section{ACKNOWLEDGMENTS}

Thanks to Mark Potts \& Daniel Colbourne of MAHLE Powertrain for their support.

\section{DEFINITIONS/ABBREVIATIONS}

BMEP: Brake Mean Effective Pressure

BSFC: Brake Specific Fuel Consumption

c.a.: Crank Angle

DI: Direct Injection

EGR: Exhaust Gas Recirculation

EIVC: Early Inlet Valve Closing

EOI: End of Injection

Page 22 of 24 
EPA: Environmental Protection Agency

EVC: Exhaust Valve Closing

EVO: Exhaust Valve Opening

FID: Flame Ionisation Detector

FSI: Fuel Stratified Injection

IMEPg: Gross Indicated Mean Effective Pressure

IMEPn: Net Indicated Mean Effective Pressure

IVC: Inlet Valve Closing

IVO: Inlet Valve Opening

ISFCn: Net Indicated Specific Fuel Consumption

iEGR: Internal Exhaust Gas Recirculation

LIVC: Late Inlet Valve Closing

MBT: Maximum Brake Torque

MFB: Mass Fraction Burned

PFI: Port Fuel Injection

RON: Research Octane Number

SI: Spark Ignition

SOI: Start of Injection

TDC: Top Dead Centre

THC: Total Unburned Hydrocarbons

ULG: Unleaded Gasoline

VLD: Variable Lift and Duration

VVT: Variable Valve Timing

WOT: Wide Open Throttle

$\eta_{\text {GE }}$ : Gas exchange efficiency

$\lambda$ : Relative air-to-fuel ratio

$\sigma$ : Standard deviation 


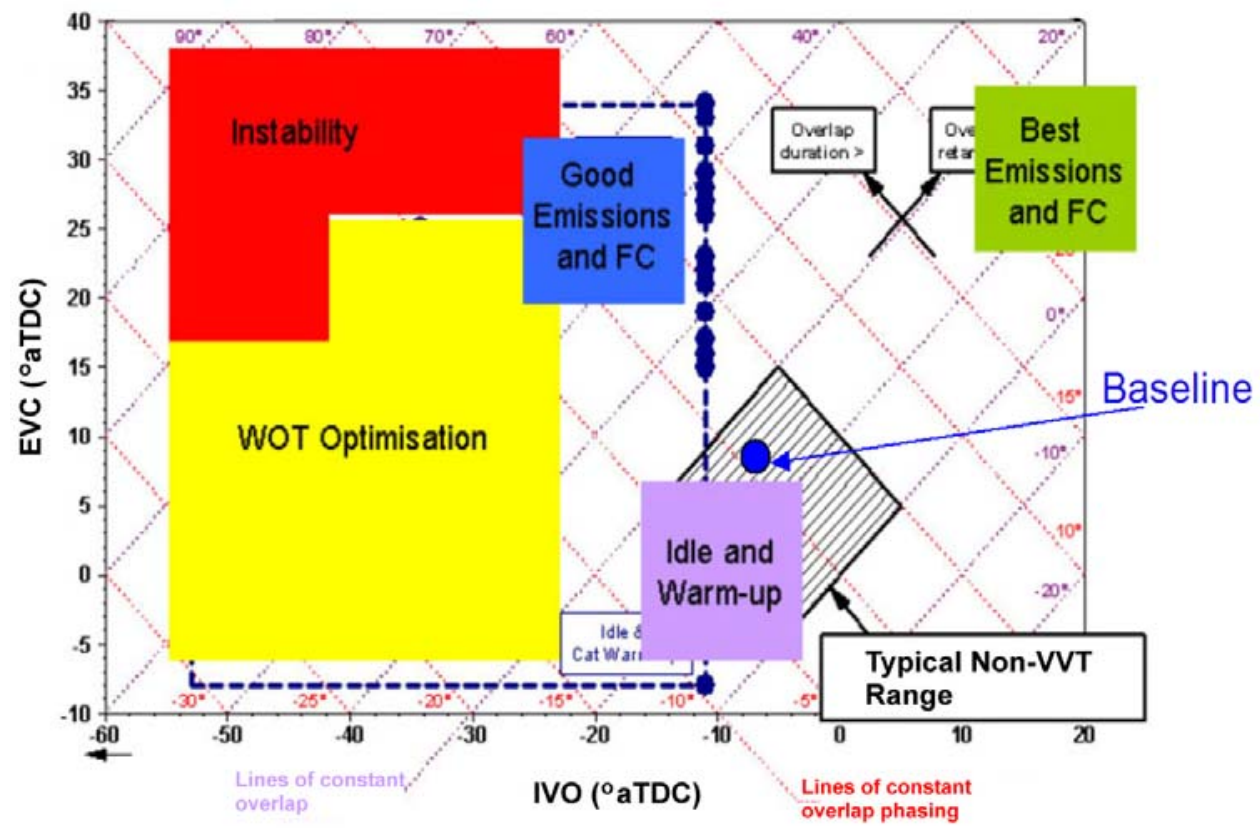

Figure A1: Valve overlap diagram showing different VVT operating strategies

Shown in Figure A1 is a map of typical valve overlap operating regimes, produced from an experimental database for numerous engines tested at MPT. The cross-hatched diamond shaped regime superimposed in the middle of the figure illustrates the typical area in which the non-VVT production SI engines tested must operate to best compromise between acceptable combustion stability at idle, part-load fuel efficiency and high load performance. The "baseline" condition used in the current work is also shown marked on the figure and can be seen to lie within this typical non-VVT valve timing regime. However, the fact that a single cylinder was used must be kept in mind, with potential cylinder-to-cylinder interactions omitted. 